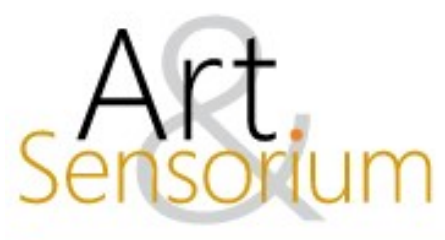

\title{
32ª BIENAL REVISITADA: ENTRE RAMIFICAÇÕES DE MICÉLIOS E COGUMELOS INCERTEZAS ADQUIREM NOVOS SIGNIFICADOS EM TEMPOS DE PANDEMIA. \\ DOI: https://doi.org/10.33871/23580437.2020.7.2.101-113
}

Márcia Helena Girardi Piva ${ }^{1}$

\begin{abstract}
Resumo: Algumas obras expostas na 32a Bienal de Arte de São Paulo, em 2016, sugerem uma nova percepção. O período de isolamento social, imposto em nossas vidas a partir de incertezas que se intensificaram no ano de 2020, buscaram nas gavetas da memória, uma mostra em que a arte deixou suas marcas. Revisitá-la em tempos de pandemia pode gerar novas interpretações. Este texto propõe uma atualização de questões que transitam entre as relações ecológicas, humanas e sistêmicas a partir de um novo cenário que se instaura para o futuro. Propõe-se a análise de duas obras que foram

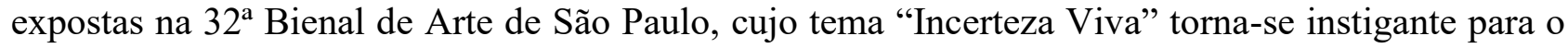
ano de 2020. Micélios, fungos e cogumelos tornam-se matéria para as obras Casa Psicotrópica e Rustle 2.0 e nos sugerem o encontro de novas formas de sentir os subterrâneos da arte que, ressignificados em tempos de total incerteza nos levam a vivenciar novas experiências.
\end{abstract}

Palavras-chave: $32^{\mathrm{a}}$ Bienal; arte contemporânea; pandemia; cogumelos; ecologia.

\section{2' BIENNIAL REVISITED: BETWEEN MYCELIA AND MUSHROOM RAMIFICATIONS, UNCERTAINTIES ACQUIRE NEW MEANINGS IN TIMES OF PANDEMIC}

\begin{abstract}
Some works exhibited at the 32nd Bienal de Arte de São Paulo, in 2016, suggest a new perception. The period of social isolation, imposed on our lives due to uncertainties that intensified in the year 2020, searched the memory drawers, a show in which art left its mark. Revisiting it in times of pandemic can generate new interpretations. This text proposes an update of issues that move between ecological, human and systemic relations based on a new scenario that is established for the future. It is proposed to analyze two works that were exhibited at the 32nd Bienal de Arte de São Paulo, whose theme "Incerteza Viva" becomes instigating for the year 2020. Myceliums, fungi and mushrooms become material for the works Casa Psicotrópica and Rustle 2.0 and suggest the meeting of new ways of feeling the underground of art that, re-signified in times of total uncertainty, lead us to live new experiences.
\end{abstract}

Keywords: 32nd Bienal; contemporary art; pandemic; mushrooms; ecology.

\footnotetext{
${ }^{1}$ Doutora e Mestre em Artes Visuais pela Universidade Estadual de Campinas - UNICAMP - SP (2015 -2010), ambos os títulos com bolsa da Fundação de Amparo à Pesquisa do Estado de São Paulo (FAPESP), São Paulo, Brasil. Graduada em Educação Artística pela Universidade Presbiteriana Mackenzie (1985). Desenvolveu pesquisa de Pós-doutorado concluída em dezembro de 2019 no Museu de Arte Contemporânea da Universidade de São Paulo MAC/USP. Em suas pesquisas dedica-se às relações das diversas áreas de conhecimento que transitam entre a arte e a ecologia a partir da análise de obras de artistas que atuam no campo da arte contemporânea. http://lattes.cnpq.br/5489050663771067. ORCID: 0000-0002-9774-5716.mgpiva@yahoo.com.br
} 


\section{2ª BIENAL REVISADA: ENTRE RAMAS DE MIELIOS Y SETAS LAS INCERTIDUMBRES ADQUIEREN NUEVOS SIGNIFICADOS EN TIEMPOS DE PANDEMIA.}

Resumen: Algunas obras expuestas en la 32 Bienal de Arte de São Paulo, en 2016, sugieren una nueva percepción. El período de aislamiento social, impuesto a nuestras vidas por las incertidumbres que se intensificaron en el año 2020, buscó en los cajones de la memoria una muestra en la que el arte dejara huella. Revisarlo en tiempos de pandemia puede generar nuevas interpretaciones. Este texto propone una actualización de cuestiones que se mueven entre las relaciones ecológicas, humanas y sistémicas a partir de un nuevo escenario que se establece para el futuro. Se propone analizar dos obras que se exhibieron en la 32 Bienal de Arte de São Paulo, cuyo tema "Incerteza Viva" se vuelve instigador para el año 2020. Micelios, hongos y setas se convierten en material para las obras Casa Psicotrópica y Rustle 2.0 y proponen el encuentro de nuevas formas de sentir el underground del arte que, resignificadas en tiempos de total incertidumbre, nos llevan a vivir nuevas experiencias.

Palabras llave: $32^{\text {a }}$ Bienal; arte Contemporaneo; pandemia; hongos; ecología.

\section{Introdução}

Muito se fala em preservação ambiental e muitas são as dificuldades sentidas em alcançar ações satisfatórias para atingir tal objetivo de forma mundial. As visões sobre este problema, que aflige toda a humanidade, ainda são bastante diversas. A natureza, ao ser colocada em pauta, é a todo tempo julgada por determinadores de seu futuro. Em alguns casos pensa-se que devemos preservar, mas, donos de terras ou especuladores se acham invadidos em seus interesses, precisam de campos para cultivo em que, a forma habitual de prepará-los é através do fogo ou do desmatamento, a natureza nesse caso deve estar fadada a nos servir, depender de nossos interesses sociais, políticos e econômicos. Essa é uma triste realidade, pois precisamos pensar que a natureza não necessita do homem para sobreviver, no entanto, sabemos que o contrário não seria possível, a humanidade não sobreviveria sem o ambiente natural. Em meio a tudo isso existem aqueles que realmente amam a natureza, conhecem sua importância e lutam para preservá-la. É interessante observar que a floresta se sustenta sozinha, não precisa do homem para crescer, florescer e multiplicar seus domínios. Se toda a humanidade desaparecesse, mesmo assim a natureza continuaria.

Devemos refletir, um pouco mais profundamente, sobre esse presente que recebemos na terra, que é a natureza inteligente e soberana. Pensemos em uma floresta intocada pelo ser humano, neste lugar idílico, temos árvores maiores e mais fortes, como uma redoma verde de proteção. Essas árvores enormes, as grandes protetoras das florestas, permitem que as menores se desenvolvam mais facilmente. Há uma interrelação entre todo esse sistema vivente, tanto nas grandes, médias, pequenas árvores ou arbustos existentes várias outras plantas irão crescer, como samambaias, bromélias, cipós e todos os tipos de hospedeiras. E assim, percebemos que uma variedade de plantas, microorganismos e animais terão nela sua moradia.

Uma camada de folhas secas cai e acumula-se no solo, assim como as sementes e restos dos frutos derrubados pelos animais. Nesse solo protegido por essa camada espessa de nutrientes, outros seres se beneficiam e começam a ali habitar. Tanto as plantas como todos os tipos de seres vivos multiplicam-se na floresta intocada pelo homem, possuem suas funções específicas para o andamento perfeito de todo um ecossistema em equilíbrio.

Podemos pensar em uma única árvore como um ecossistema completo, com pássaros, saguis, insetos, aranhas e tantas outras coisas que crescerão em torno dela. O que é mais admirável é saber que uma árvore saudável consegue transmitir pelas suas raízes uma massa de nutrientes para uma outra vizinha, que esteja com algum tipo de escassez. A natureza é poesia. Uma espécie totalmente diferente consegue delegar uma parte de seu alimento para uma árvore doente. Poderíamos dizer que essa 
enorme comunicação entre as árvores pelas raízes, por onde entram e saem nutrientes e informações, seria uma espécie de rede de internet que trabalha entre elas e que se encontra de baixo do solo.

Neste texto gostaria de destacar essa poesia que é a própria natureza, uma natureza que se supera e sempre se recupera por sua própria inteligência. Procura seus caminhos entre o aéreo, solo ou subsolo. Um pouco como a arte faz buscar caminhos nunca percorridos. Olhares e formas inovadoras se voltam para o espaço que nos abraça, para nossas raízes, para os ramos que fizeram multiplicar nossa essência. Nos indica caminhos a percorrer e avanços, a cada dia, para nos mantermos inteiros e renovados.

\section{Os subterrâneos da arte ressignificados em tempos de incerteza na $32^{\mathrm{a}}$ Bienal}

A arte é um território possível para articulações de pensamentos e ações, assim como propício para um olhar crítico que busca reinventar e refletir o mundo. Essa reflexão sobre a conexão existente entre o ambiente natural e a arte, me impulsionou a revisitar uma mostra que aconteceu no ano de 2016, a 32 $2^{a}$ Bienal de São Paulo, cujo tema "Incerteza Viva" nos lançava em um território de instabilidades e incertezas, que englobava reflexões primordiais sobre as ações do homem e suas consequências sobre o destino do planeta.

A incerteza sobre o futuro do Brasil e do mundo, a partir dos desequilíbrios sociais, econômicos e políticos, ligados à temática ambiental, foram assuntos tratados na $32^{\mathrm{a}}$ Bienal de São Paulo, que incluíam reflexões sobre multiculturalismo, política de gênero, transdisciplinaridade, artistas de países periféricos, intercâmbios geracionais entre outras questões permeadas, muitas vezes, por uma boa dose de utopia. A ecologia era, com certeza, o tema presente em grande parte das obras, no entanto, esse não era o único eixo a ser discutido. No espaço da Bienal o tema da ecologia propunha várias vertentes. A ecologia subjetiva estaria relacionada ao que produzimos culturalmente, através de nossos pensamentos, costumes e tradições. A ecologia social seria aquela que engloba relações de poder e economia. E a ecologia ambiental referia-se aos recursos naturais e à reflexão sobre a sobrevivência do planeta. Os assuntos, que de forma geral transbordavam incertezas, mostravam-se através de diferentes aspectos e evidenciavam sua permanência pelo simples fato de se estar vivo.

Sentida tanto nas humanidades como nas ciências, a incerteza parece controlar os modos pelos quais entendemos ou não nosso estar no mundo hoje: degradação ambiental, violência e ameaças a comunidades e à diversidade cultural, aquecimento global, colapsos econômicos e políticos, catástrofes naturais, vida devastada por atrocidades, doenças e fome são as matérias que nos circundam. (VOLZ, 2016, p.21)

O simples fato de se estar vivo gerar tantas incertezas foi a questão que me atraiu a pensar em revisitar algumas obras expostas na $32^{\mathrm{a}}$ Bienal, a partir de um novo cenário que agora se apresenta em nossas vidas. Se tal evento fosse concebido após o período que vivenciamos hoje - o ano de 2020 -, diríamos que discussões a partir do tema "Incerteza Viva" aconteciam pelo fato de termos passado por um momento de pandemia, que nos colocou em isolamento social e diante de muitas incertezas. Restritos, cada um ao seu espaço, trancados em casa, toda essa situação que experimentamos em 2020, transformou nossas vidas abruptamente. Foi o ano em que o mundo parou. Principalmente no início de toda essa mudança, parecia mais estarmos vivendo em um filme de ficção científica do que na própria realidade. Ruas e parques vazios, teatros, cinemas, escritórios, lojas com suas portas fechadas, algo que nossa geração nunca havia presenciado, um grande vazio - um ano em suspensão. Foi quando o tempo reduziu sua velocidade, e nos fez parar. Resgatados de exterioridades cotidianas, proporcionou viagens em nossos subterrâneos. Nos fez olhar para o outro, tentar alimentar os que necessitavam e socorrer os que precisavam, como as raízes de uma frondosa árvore em uma floresta intocada. E assim, o convite que proponho aqui é entrar novamente pelos espaços da Bienal Incerteza Viva, como uma oportunidade de imergir em um território onde o pensar sobre questões de incerteza podem, agora, vivenciar novas experiências. 
Em meio a pandemia tornou-se oportuno revisitar virtualmente, ou a partir de memórias registradas, algumas obras e artistas. Podemos retornar aos espaços vivenciados da arte em outros tempos e ressignificar questões que nos falam poeticamente sobre a vida através da arte e da natureza.

Ficamos em casa, os parques floresceram, as plantas ocuparam novos espaços, os animais sentiramse mais à vontade para caminhar em locais não antes experimentados. Nós nos sentimos trancados, e a natureza viva e liberta. De dentro de nossas casas, o canto dos pássaros, o ruído do vento, o sol refletido em cada planta e a lágrima da chuva suprindo as necessidades do solo, ainda seriam formas de sentir a liberdade excluída de nossas vidas. Com a correria de afazeres, compromissos e horários pouco sobrava para nós mesmos. A partir da natureza exterior observada descobrimos uma natureza interna mais sensível e a arte que dela emana. A arte está sempre presente, livre como a natureza nos ensina a enxergar além de nossos próprios olhos.

Essa interligação entre a arte e a natureza foi um dos aspectos interessantes da $32^{\mathrm{a}}$ Bienal, a exposição ultrapassava os limites do edifício projetado por Oscar Niemeyer e se projetava para além das paredes de vidro, que possibilitavam uma conexão entre as obras e o Parque do Ibirapuera. Para Jochen Volz, curador da Bienal, a concepção da mostra deveria refletir-se a partir da seguinte ideia: "INCERTEZA VIVA é construída como um jardim, onde temas e ideias se tecem livremente em um todo integrado, estruturado em camadas - a tentativa da ecologia em si mesma" (VOLZ, 2016, p.26).

A mostra, buscou um caráter permeável e acessível, "apoiou-se em poucas paredes e espaços generosos que respeitaram a autonomia de cada obra e incentivou o entrelaçamento de ideias, e conseguiu deixar o parque entrar no local da exposição, que propunha a abertura a diferentes pontos de vista e metodologias de vida juntos". (BRENNER, 2017)

A ideia de revisitar esse jardim proposto para a Bienal Incerteza Viva, seria um passeio que gostaria de iniciar a partir dos cogumelos, que tanto haviam me encantado no ano de 2016. Eles sempre me foram simpáticos. Havia diversos artistas que os utilizavam como matéria para suas obras. Foram inúmeros sábados que eu retornava à Bienal de São Paulo para acompanhar o desenvolvimento desses seres vivos encantadores.

A obra Casa psicotrópica: Pavilhão zooético de tecnologias ballardianas [Fig.1], encontrava-se no piso térreo da Bienal. Executada pelos artistas lituanos Nomeda \& Gediminas Urbonas ${ }^{2}$, a obra foi inspirada nas narrativas ficcionais de Vermilion Sands (1971)

\footnotetext{
2 Nomeda \& Gediminas Urbonas são artistas, educadores e professores do Programa MIT em Arte, Cultura e Tecnologia. Além disso, eles são professores visitantes da CAFA em Pequim, VDU em Kaunas, NABA em Milão e luav em Veneza. Os Urbonas são fundadores do US - Urbonas Studio, que combina as disciplinas de novas mídias, urbanismo, ciências sociais, ecologia e pedagogia em uma prática artística integrada. Seus trabalhos foram exibidos nas bienais de São Paulo, Berlim, Moscou, Lyon, Gwangju, Busan, Veneza; Exposições Manifesta e Documenta. Em 2018, eles fizeram

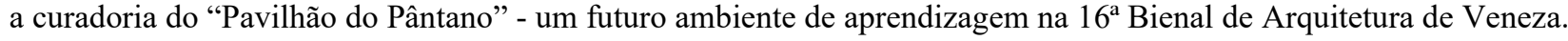




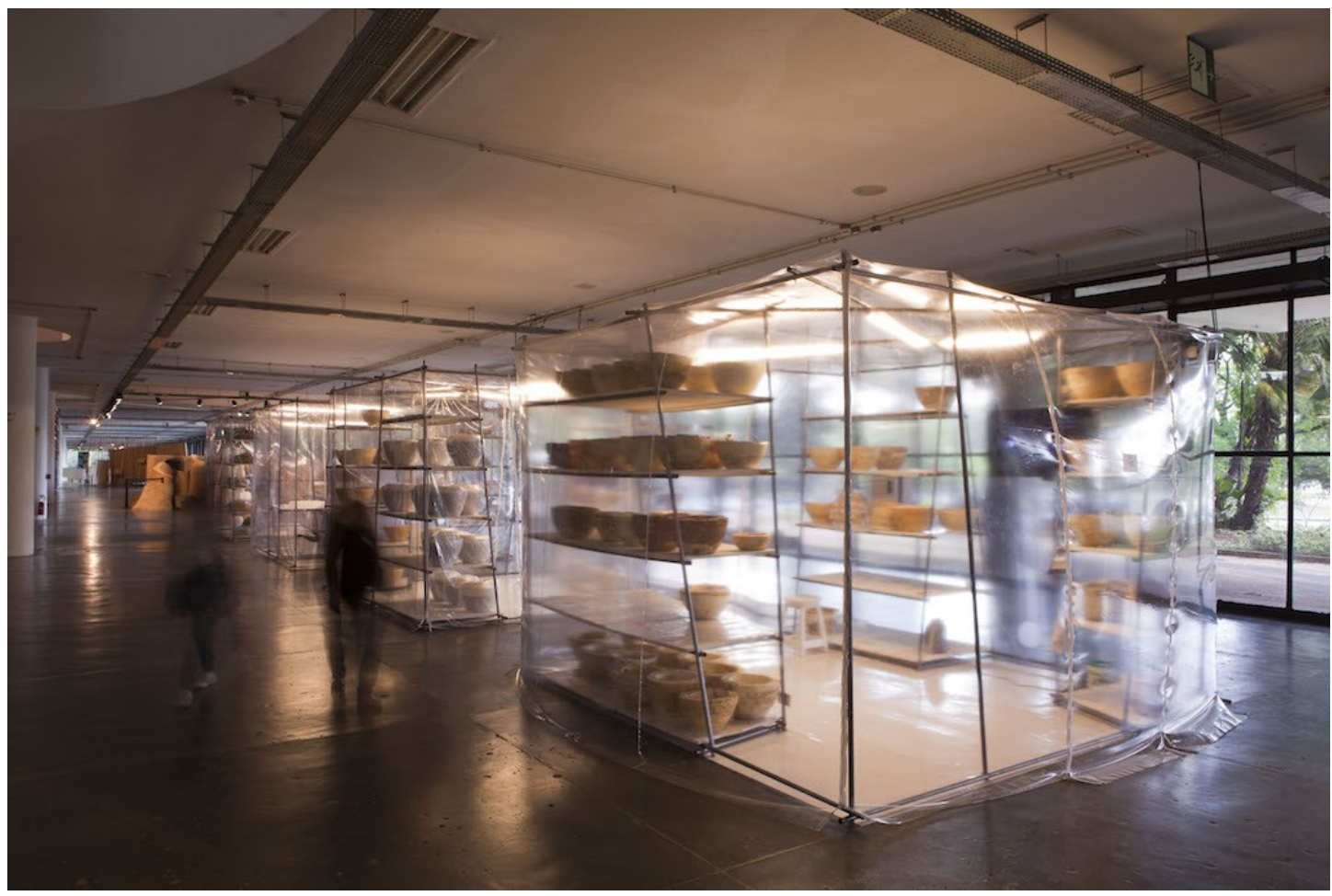

Figura 1- Nomeda e Gediminas Urbonas, CasaPsicotrópica: Pavilhão Zooetics of ballardian Technologies, 2016. Vista da Instalação, 32 B Bienal de São Paulo. Fundação Bienal de São Paulo, São Paulo, Brasil, 2016. Foto: Pedro Ivo Trasferetti/Fundação Bienal de São Paulo. Fonte: BRENNER, 32ª Bienal de São Paulo, 2017.

O autor do livro, o inglês J. G. Ballard, cria um ambiente inquietante em torno de uma história sobre um resort de nome Vermilion Sands. Um lugar para não se enraizar seriamente, dizem alguns leitores. Talvez algo lançado no futuro, um futuro jogado em um mundo quase irreconhecível. No livro, a paisagem e a ecologia surrealista que as palavras fazem imaginar revela desde plantas que cantam de forma harmônica a "esculturas sônicas" que vibram e crescem como se estivessem vivas. Um mundo diferente se instala na imaginação dos leitores ao descrever roupas que seriam fiadas com fios vivos e máquinas de poesias que dispensam a necessidade dos poetas e poetisas.

Pavilhão Zooético inspira-se nos contos encontrados em Vermilion Sands (1971), um livro de ficção científica do autor inglês J.G.Ballard que imagina um mundo onde os dispositivos tecnológicos estão vivos e sensíveis, um mundo onde as casas, por exemplo, são capazes de responder aos estados emocionais de seus habitantes. O trabalho investiga como as relações entre vida e não vida, humano e não humano, podem ser, por um lado, incognoscíveis, permanecendo não mapeadas pelas cartografias de conhecimento existentes e, ao mesmo tempo, necessárias e inevitáveis. O Pavilhão Zooético exige, portanto, novas formas de imaginação estética e científica. (US Urbonas Studio, 2016).

A descrição sobre o universo fantástico que envolve a história do livro, menciona a investigação das relações "vida e não vida, humano e não humano" e a conexão entre os dispositivos tecnológicos e o estado emocional das pessoas com o ambiente. Essas referências seriam sutilmente perceptíveis no laboratório que encontrávamos na Bienal para apresentação da obra dos artistas lituanos. O local montado no espaço do evento poderia ser observado como uma obra viva, que deixava aflorar novas formas de imaginação, tanto estética como científica.

Os visitantes poderiam encontrar na Casa Psicotrópica: Pavilhão Zooetics of ballardian Technologies todos os elementos necessários para o cultivo de cogumelos, se assim o quisessem. $\mathrm{O}$ espaço era climatizado e esterilizado de forma adequada, com segurança a não haver nenhuma contaminação. As paredes transparentes permitiam ver o laboratório a funcionar, com os visitantes inscritos munidos de aventais e luvas a receber instruções e, em seguida, executar as ações para 
cultivar diversos tipos de cogumelos. Para o cultivo utilizava-se uma composição formada por uma mistura de ingredientes à base de micélios, moldados em forma de vasos, onde os novos seres iriam se desenvolver.

Como no livro de Ballard as mais diversas formas apareciam brotando dos vasos [Fig.2], projetavam suas curvas poéticas para além da estrutura inicial e pareciam tecer, com fios vivos, uma aparência inusitada que se desmembrava em variadas dimensões. A cada semana os cogumelos se desenvolviam e surpreendiam, como esculturas vivas, que cresciam naquele ambiente. Nada poderia ser determinado, suas formas surgiam aleatoriamente e de maneira incerta, uma incerteza viva. Um mundo paralelo e totalmente diferente se modificava a cada momento. Suas curvas compunham uma visão poética, uma dança harmônica de visões musicais. $O$ ambiente atraía o visitante que o observava através de uma parede transparente em material plástico que servia de barreira entre o espectador e a obra - um distanciamento necessário para evitar contaminações. Era possível visualizar todo o espaço e sentir um mundo diferente que se processava e levava o observador a alcançar percepções imaginativas que provocavam a fuga da realidade.

A obra em questão, poderia traçar algumas relações com o momento atual, de isolamento social. O distanciamento necessário nos livra da contaminação. Observamos um mundo em que estamos ao mesmo tempo, dentro e fora. Fazemos parte dele, mas não podemos entrar. Quem está na linha de frente não pode sair, não sabemos bem o que irá acontecer e qual é nosso lugar. Tantas formas inusitadas se criam para nos fazer sair, em passeio com a imaginação para uma nova vida não antes imaginada. Rostos cobertos por máscaras desdobram-se em hábitos diferentes, instalados num mundo modificado por seres invisíveis que colocam em risco nossa sobrevivência. Nesse contexto, deixamos a realidade transformar-se, assim como a vida vista a partir da arte.

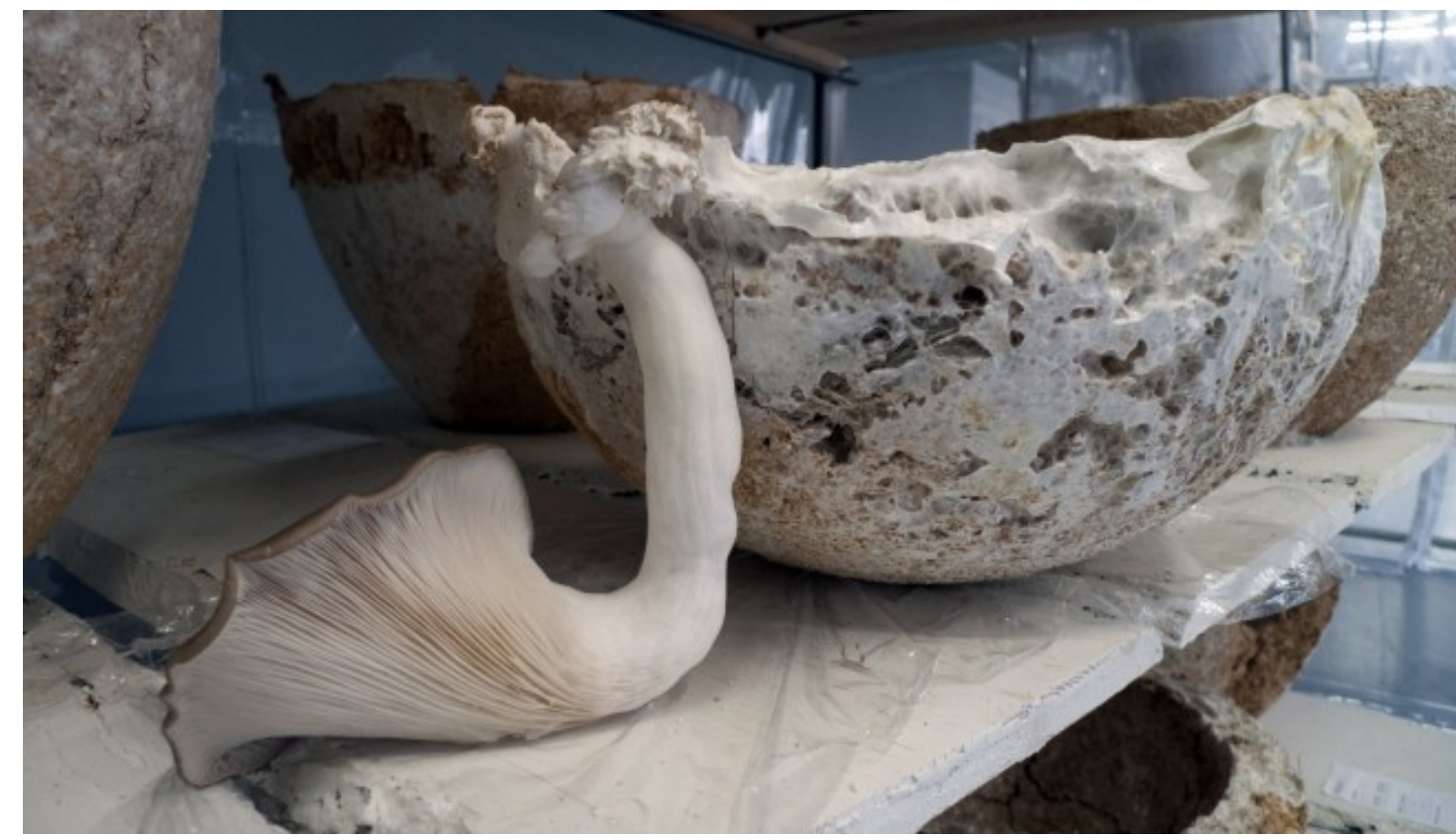

Figura 2 - Psychotropic House: Zooetics Pavilion of Ballardian Technologies [Casa psicotrópica: Pavilhão zooético de tecnologias ballardianas], 2015- 2016. Instalação com micélio, café, resíduos agrícolas, metal e PVC. Vista da instalação na XII Baltic Triennial, CAC, Vilnus, Lituânia (2015). Fonte: Catálogo Incerteza Viva- Bienal de São Paulo, 2016, p.287.

Em 2020, os dispositivos tecnológicos passam a ocupar um novo espaço em nossas vidas, e nossas casas parecem mesmo aproximar-se daquelas descritas por Ballard, claro que com suas devidas proporções, pois os dispositivos vivos e sensíveis de Vermilion Sands - que fariam a imaginação viajar em um tempo inalcançável - passam a dar lugar aos tablets e celulares, que em tempos de 
pandemia ocupam espaços quase capazes de responder aos estados emocionais de seus portadores ao permitir comunicações em rede, mais distantes e sensíveis, que se tornam essenciais.

O ambiente criado pelos artistas Nomeda \& Gediminas Urbonas, se diferenciava do ambiente natural, mas nos aproximava de outras questões. Como as raízes das grandes árvores que doam seu alimento a outras, assim também acontece com os cogumelos. Estes tão simpáticos seres viventes possuem muitas qualidades, não só culinárias e medicinais, mas também uma estrutura que interliga os subterrâneos como uma rede de internet. A conexão entre o tema proposto pelo curador da Bienal, Jochen Volz, e sua equipe de cocuradores enfatizaram que a arte contemporânea pode nos guiar para habitar a incerteza ao invés de temê-la. Essa ideia de não deixar vencer-se pelo medo, mas sim adaptar-se, enfrentar e resistir, permeava as obras expostas que ecoavam muitas questões sociais e culturais em uma interligação pelos subterrâneos invisíveis. Promover redes e afetos entre os espaços submersos, abrindo-se a múltiplas perspectivas, entre ideias que se tecem em um todo integrado encontravam-se nas ramificações dos micélios e nas camadas ecológicas propostas.

Essa edição da $32^{\mathrm{a}}$ Bienal, de acordo com Fernanda Brenner ${ }^{3}$, foi apelidada de "Bienal dos Cogumelos" em referência a obras como a Casa psicotrópica de Nomeda e Gediminas Urbonas entre outras de artistas de nacionalidades diversas. Segundo Volz ${ }^{4}$ eram sete os artistas que trabalhavam com micélios, cogumelos ou fungos. Tais artistas buscaram relações com questões sobre as incertezas, porém de maneiras diferenciadas.

O micélio é uma inteligência que pensa sistematicamente. Ele reage, ele compensa, ele tira de um e dá para o outro, ele transporta informação, ele cria uma rede... isso é muito interessante quando você percebe a incerteza e não sabe para onde vai. Por outro lado, víamos artistas buscando informações, ideias ou inspiração, através de uma solução que não é humana, mas que busca uma resistência. Eram sete artistas que trabalhavam com eles, um fenômeno que pode ser refletido de muitas maneiras [...]. Sobre os "seres vivos mais antigos do planeta" é curioso pensar como conseguem se transformar, e como um transporta a energia da luz para o outro que está mais embaixo, distante da luz. (VOLZ, informação verbal, 2019).

O micélio tornou-se matéria prima para muitas obras na $32^{\mathrm{a}}$ Bienal. Consiste na parte vegetativa de um fungo, constituída por uma massa de ramificações chamadas hifas. Essas ramificações vão se reproduzindo como fios emaranhados, que carregam nutrientes necessários para a reprodução dos fungos. As extremidades das hifas, em condições favoráveis, crescem rapidamente e vão penetrando cada vez mais no substrato, exploram o espaço em que se encontram à procura de sua subsistência. Esse emaranhado de ramificações, que aguçaram a reflexão de vários artistas, provocava esse pensamento sobre as redes de comunicação, hoje representada pela Internet. Essa proposta poderia ser percebida através de um mundo paralelo, tornado crucialmente diferente que proporcionava uma conexão entre as obras expostas no espaço da mostra.

\footnotetext{
${ }^{3}$ Fernanda Brenner é curadora independente e diretora artística estabelecida em São Paulo. Fundou em 2012 o Pivô, um espaço de arte contemporânea sem fins lucrativos em São Paulo, onde ela atua como diretora artística. Recentemente, Brenner foi a curadora de "Neither", na Mendes Wood DM, Bruxelas. Seus textos já passaram pela Frieze, Artreview, Terremoto, além do The Exhibitionist, onde ela também faz parte do conselho editorial.

${ }^{4}$ Jochen Volz, atual Diretor Geral da Pinacoteca do Estado de São Paulo, concedeu-me gentilmente uma entrevista, em 31 de outubro de 2019. Durante nossa conversa na Pinacoteca, contou sobre sua trajetória como curador, especialmente no Instituto Inhotim e na $32^{\mathrm{a}}$ Bienal de São Paulo.
} 


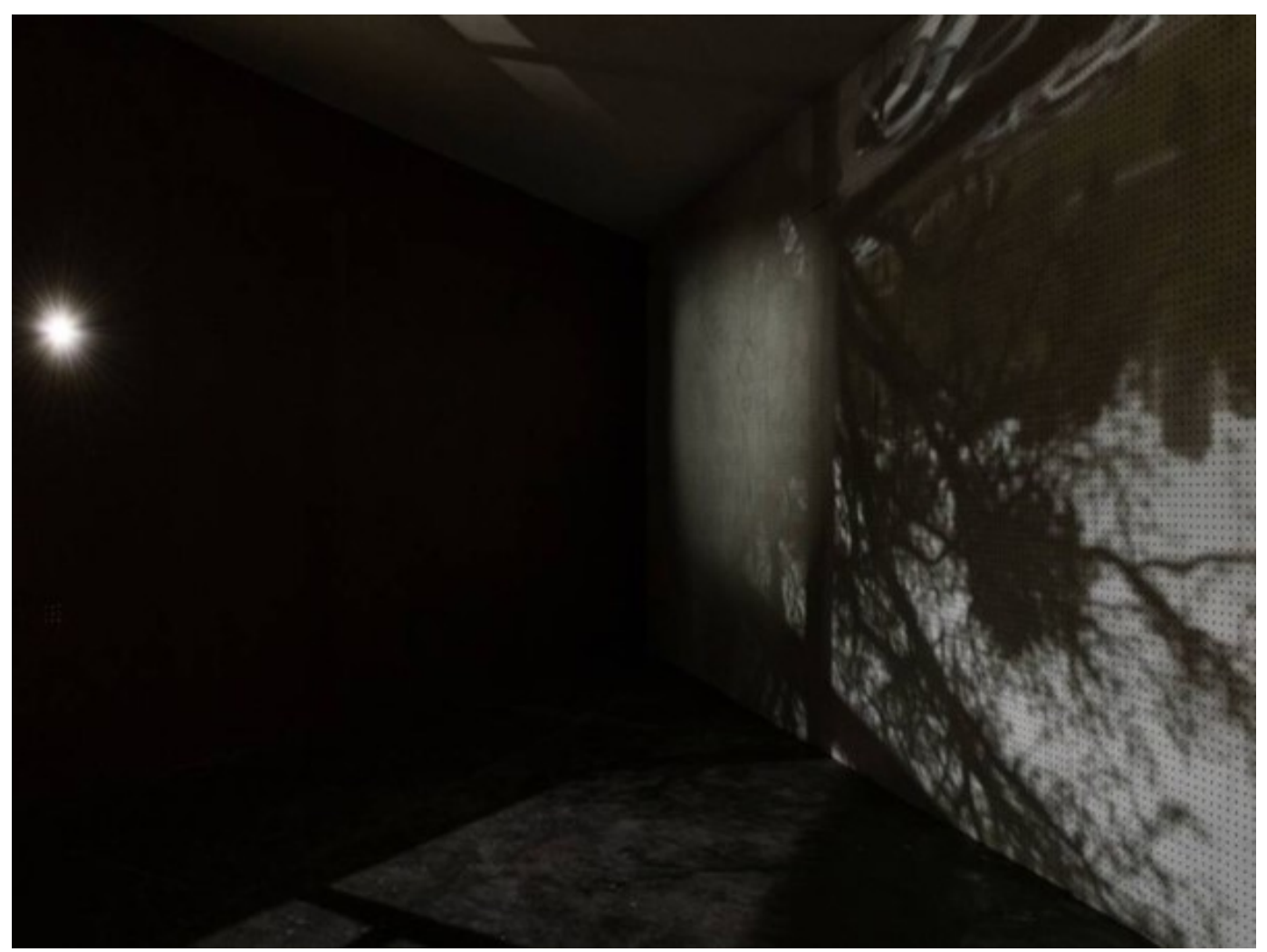

Figura 3 - Em'kal Eyongakpa. Entrada da Instalação Rustle 2.0 - 32 a Bienal Internacional de São Paulo, 2016. Fonte: Catálogo Incerteza Viva - Bienal de São Paulo, 2016

A partir de um tom de curiosidade éramos convidados a entrar em uma instalação que não permitia saber o que nos esperava em seu interior. O exterior era apenas uma brecha com sombras refletidas em meio a uma atmosfera sinistra e escura que emitiam sons que atraiam o visitante a entrar.

A obra do artista Em'kal Eyongakpa ${ }^{5}$ tratava-se de ambiente sonoro envolvente, uma instalação com elementos orgânicos e com a sutileza de um mundo eletrônico que interagia [Fig.3], um espaço que se tornava mágico por sua pouca visibilidade, onde micélios fúngicos revestiam todo o ambiente, escuro e sinistro. Um mundo regado com sons gravados em ambiente natural - ruídos de pássaros, de água, de povos nativos e de árvores ao vento - mas que também nos projetava aos sons estrondosos dos desastres naturais ou catastróficos, que se pronunciavam e delatavam as interferências caóticas da humanidade.

\footnotetext{
${ }^{5}$ Em'kal Eyongakpa nasceu em 1981, Mamfe, Camarões - África. Vive Na Região Sudoeste do Camarões e em Amsterdã,
} Holanda. 


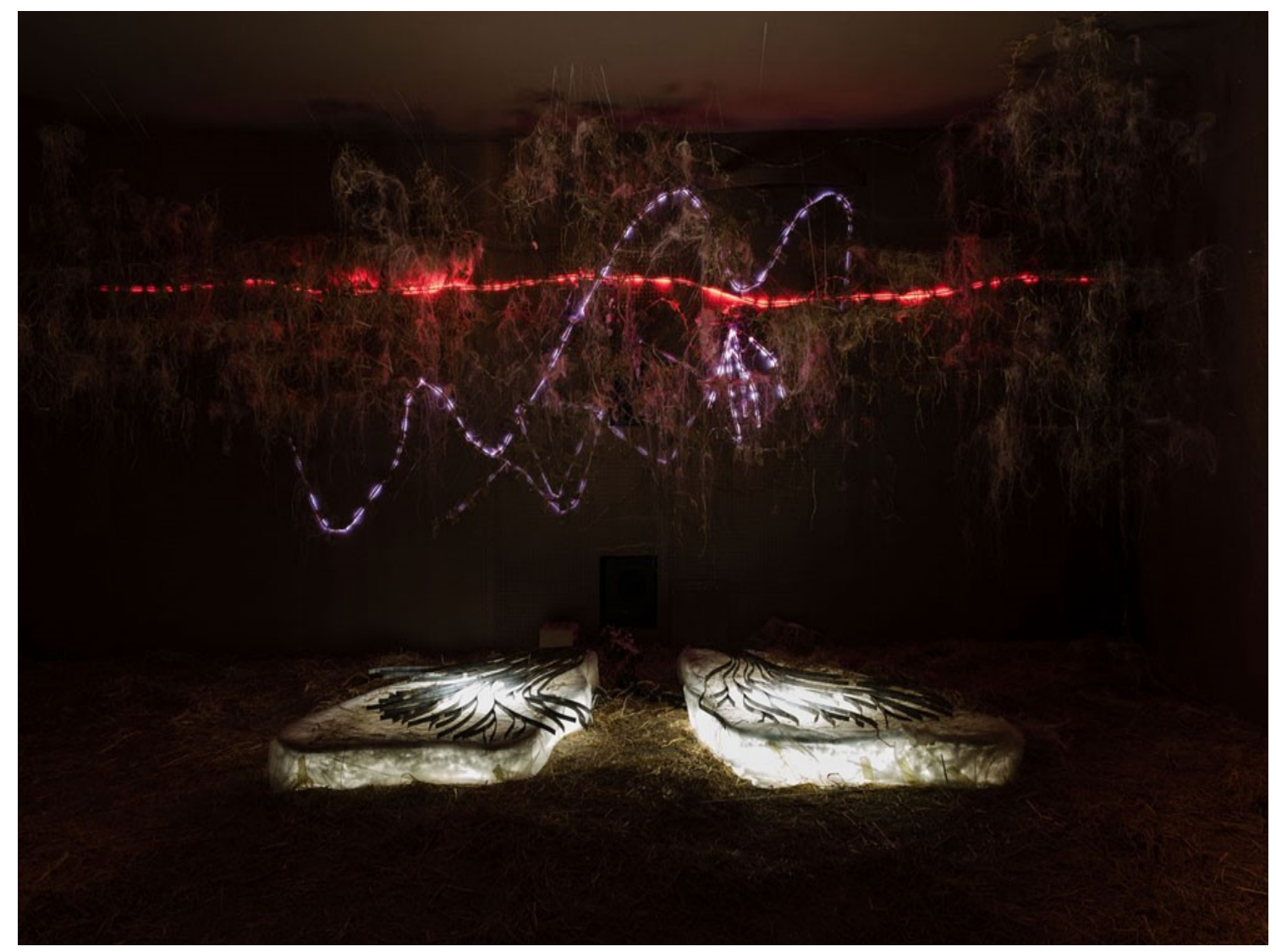

Figura 4 - Em'kal Eyongakpa. Interior da Instalação Rustle 2.0 - 32 ${ }^{\mathrm{a}}$ Bienal Internacional de São Paulo, 2016. Fonte: Catálogo Incerteza Viva - Bienal de São Paulo, 2016.

A instalação, Rustle 2.0 [Fig.4], criada pelo artista africano Em'kal Eyongakpa, e exposta no ano de 2016, envolvia-nos de forma sensorial. O som antes tranquilo e harmônico de uma floresta selvagem é surpreendido por outros de derrubada de árvores, de gritos de animais, pássaros assustados e de povos nativos - no momento da expulsão de seu ambiente natural. Essa sensação, invadia nosso interior de forma inesperada, e era transmitida através do ruído de motosserras, que parecia adentrar com toda violência no ambiente que antes nos parecia harmonioso e equilibrado. Essa interrupção do fluxo da vida, então sugerida pelo som que compunha a instalação, intensificava o pensamento sobre a necessidade de preservação do ambiente natural e de algumas consequências que podem ocorrer a partir do desequilíbrio da natureza.

Baseando-se na atribuição de inteligência pela cibernética a atores não humanos, as gravações de áudio de Eyongakpa dos biomas da Bacia do Congo e da floresta amazônica, bem como aquelas que registram incursões externas - como motosserras, queda de árvores e tráfego aéreo - transmitem uma sensação assíncrona de espaço. A paisagem sonora composta é então sincronizada com luzes LED, criando padrões visuais rítmicos e estruturas de parede customizadas compostas de fibras vegetais que são mantidas juntas por biopolímeros (filamentos de micélio) e micélio, a parte vegetativa de um fungo composto de uma rede de filamentos brancos (hifas). As cordas de luz são uma reminiscência de eletrocardiogramas ou feeds de bolsa de valores - fluxos representacionais de informações em tempo real - que são conectados a uma interface que também controla o Breathe II (2013). Esta escultura no centro da instalação simula padrões de inspiração e expiração, bem como de repouso, e está ligada a dispositivos de levitação eletromagnética e à difusão ambiente de luz através de uma densidade de material fibroso semelhante ao crescimento da vegetação tropical. (SHARJAH ART - 13 Bienal de Sharjah. Em'kal Eyongakpa selected works, 2016)

R. Inter. Interdisc. Art\&Sensorium, Curitiba, v.7, n.2, p. 101 - 113 Jul.- Dez. 2020 
Na obra de Em'kal, o som do universo da mata que se instaurava em meio a um ambiente envolto pela escuridão, e as paredes e chão da instalação recobertas de micélio, pouco visíveis, provocavam uma sensibilização através do cheiro e de texturas da natureza que invadia o lugar. A iluminação que vinha através de algumas sequências de LED, nos chamava a atenção, pois as luzes simulavam um movimento rápido, sequencial e em fluxos, como o sangue que em nosso corpo é bombeado através das veias e artérias. Este cenário nos transportava para um campo cibernético. Na instalação do artista, dois objetos iluminados, representação dos continentes africano e sul americano, simulavam pulmões, e as mangueiras de LED que pareciam recarregar os "continentes pulmões" [Fig.10], poderiam ser interpretadas como uma forma artificial de respiração. Novas reflexões fluem, sobre a experiência vivenciada, a partir do novo cenário que se instala em nossas vidas.

O Adendo "2.0" no próprio título da obra parece revelar o futuro, o ano de 2020, quando uma atualização da obra, exposta em anos anteriores, parece necessitar de uma complementação. A palavra "adendo" tem como significado: acréscimo que corrige, explicita, ratifica ou complementa um determinado texto, livro ou obra; um apêndice, ou suplemento. E no momento que partimos de 2016, para retornarmos à obra em 2020, precisamos mesmo - considerando que a arte se atualiza complementar, ou acrescentar uma nova percepção que a ela se insere. O pensar sobre questões de incerteza inclui agora um ser invisível que nos fará vivenciar novas experiências.

No ano de 2020, a dependência aos meios eletrônicos se intensifica entre todos, mesmo aqueles que se sentiam às margens da tecnologia se viram, muitas vezes, obrigados a servir-se de tais meios como única possibilidade de diálogo com um mundo que nos trancava dentro de nossas casas. Invadido pelo perigo de um vírus, a natureza, a cultura e a ciência passam a habitar uma nova conexão e farão parte de um todo interligado.

Diversas pandemias já foram causadas por vírus transmitidos de animais para humanos, como HIV, Sars-CoV e Sars-CoV-2. Essas e outras patologias podem ser causadas pelo desmatamento contínuo para uso agrícola do solo ou habitação humana, aproximando animais silvestres e seus vírus das pessoas. É o que afirma um novo estudo publicado na revista Landscape Ecology.

A pesquisa buscou entender como os comportamentos humanos podem influenciar o aumento da incidência de doenças, em especial com a prática do desmatamento. Com a fragmentação de habitat, os seres humanos passaram a ter um contato mais frequente com animais silvestres.

Pelo menos 70\% das enfermidades registradas desde a década de 1940 tiveram origem em animais, segundo relatório da Organização das Nações Unidas para Agricultura e Alimentação (FAO). (Estadão Saúde Summit, 13 de maio de 2020).

O desmatamento, ao fazer com que as espécies selvagens percam seu habitat e passem a viver próximas às pessoas, podem trazer ameaças invisíveis, alguns vírus que tenham como consequências as pandemias. Nesse contexto, pensemos na obra de Em'kal a partir de uma reflexão sobre o momento atual, o ano de 2020. Ao simular as redes em conexão, tanto pelos micélios que cobriam todo o espaço da instalação quanto pelas luzes LED que se movimentavam ao percorrer um circuito sequencial -, pensemos sobre o momento de isolamento social, necessário por conta da pandemia que ameaça a todos, e de nossa dependência, cada vez maior, pelas redes virtuais de comunicação. Vimos então, na instalação artística, a simulação das redes de internet que hoje habitam nossos ambientes, tornandonos praticamente dependentes de um mundo virtual que passa a tomar o lugar do que antes era natural. A imagem dos continentes pulmões nos remete a uma questão que se tornou atual no ano de 2020 . A necessidade de serem recarregados através de uma energia artificial, nos remete diretamente aos respiradores, tão necessários às complicações manifestadas pela COVID- 19, que traz inflamações por vezes irrecuperáveis aos aparelhos respiratórios, ameaça que invadiu todos os continentes, sem 
precedentes ou distinções. Essas reflexões partem de um contexto atualizado, o que na época não poderia ser correlacionado.

Rustle 2.0 (Farfalho 2.0) representava um ecossistema vivo (2016), os ruídos vindos de ventos remotos se revestiam com elementos orgânicos e cibernéticos que inferiam sobre o impacto da humanidade na natureza. Farfalho, portanto, refere-se ao significado de sons produzidos pela natureza, como das folhas das árvores que balançam ao vento e reclamam sobre a falta de preservação do meio ambiente a partir das inconcebíveis ações humanas. Eyongakpa propôs a ideia do orgânico para a sobrevivência e a manutenção dos diversos sistemas - digitais, ecológicos, políticos - ao antecipar a familiaridade entre eles. Sua criação sugere a negociação entre a ciência, a vida e a arte. A tecnologia presente nas instalações artísticas de Em'kal revela a atualidade que se instaura em suas paisagens sonoras. A mídia, tão presente em nossas vidas em tempos difíceis de isolamento social, também pode alterar noções do real e do ilusório.

Segundo Fernanda Brenner (2016), nossos sistemas políticos atuais falharam. A curadora afirma que o poder político, em todo mundo, está extrapolando os limites dos sistemas em que opera. Ela afirma que "se um apocalipse nuclear, uma mudança de paradigma, uma nova cosmologia ou o colapso de nossa civilização nos espera", a arte contemporânea, ao invés de temer a incerteza, nos impulsiona a convivermos de uma forma inteligente com ela, buscando formas equilibradas em nosso viver.

A $32^{\text {a }}$ Bienal teve "como eixo central a noção de incerteza, a fim de refletir sobre atuais condições da vida em tempos de mudança contínua, e sobre as estratégias oferecidas pela arte contemporânea para acolher ou habitar incertezas". (UFMT, 2017).

\footnotetext{
$\mathrm{Na}$ introdução ao tema ambiental da bienal, Júlia Rebouças destacou a importância de se discutir as 'incertezas' verificadas em outros campos da atuação humana, como o político e o social, como forma de conviver com o desconhecido. "É essencial que se desvincule a incerteza do medo" [...] "Incerteza Viva provoca o cidadão para que ele reflita sobre o processo pelo qual passamos agora. Fracassamos como sociedade? O modelo econômico que se apresenta, do capitalismo, serve a todos? Precisamos pensar um novo modelo de ocupação do mundo, e vemos na arte uma força transformadora da vida, que pode contribuir para um espaço inclusivo". (UFMT, 2017).
}

Tais questões que a cocuradora da $32^{\mathrm{a}}$ Bienal, Júlia Rebouças, chama a atenção em 2016, ampliamse para novas interpretações em 2020. O fracasso para conscientizar uma sociedade desigual aflora em tempos de pandemia, assim como o modelo econômico, que desvela sua fragilidade e o mundo perde o controle do que antes aparentemente parecia ser controlável.

A arte se compromete com a vida, a interpretação da realidade traduzida pela imaginação criativa do artista busca estimular a reflexão e o espírito crítico. Na busca da equação da vida, a reflexão sobre as bases da existência e da integração do pensamento e das ações humanas no contexto da atualidade, enfatiza a importância do progresso equilibrado e sustentado.

A arte nos interroga sobre diversas questões, entre elas o desenvolvimento de uma condição de oportunidades para o futuro, onde a consciência ecológica - em suas diversas vertentes - nos faz pensar em um mundo com recursos exauríveis, onde nossa responsabilidade está em perceber as possibilidades do amanhã. A arte permite disseminar ideias e ações, que como hifas vão se reproduzindo através de fios emaranhados que carregam nutrientes - que nada mais são do que os reflexos do universo em que estamos inseridos - necessários para a criatividade do artista.

\section{Considerações finais}

Há um desejo de usar cada vez mais as ferramentas da arte para a imaginação, a invenção, a experiência, e outras formas de organizar nossas reflexões sobre o nosso entorno. Revisitar a $32^{\mathrm{a}}$ 
Bienal enfatizou que as incertezas sobre o futuro estão sempre em renovação, novos olhares foram lançados a partir de um mundo em transformação. Evidenciou-se que a arte se atualiza e acompanha novas situações que se inserem no mundo, como em tempos de pandemia que vivenciamos no ano de 2020. Novas interpretações foram consideradas para as duas obras revisitadas na $32^{\text {a }}$ Bienal, intitulada "Incerteza viva", que ocorreu no ano de 2016.

$\mathrm{Na}$ mostra referida tudo se interligava, o próprio espaço de alimentação foi estruturado como uma obra integrada à atmosfera gerada pelo ambiente da Bienal, que se conectava com todas as outras obras e era experimentado pelos visitantes, que interagiam com o todo através de uma alimentação saudável que respeitava o pensamento gerado pela exposição.

Nossa grande lição parte da conscientização, de que fazemos parte de uma grande teia. Como os micélios utilizados em diversas obras da $32^{\mathrm{a}}$ Bienal, são várias as ramificações que se cruzam nos subterrâneos de nossas vidas. Partes se mostram, outras se escondem, mas somos todos uma parte da teia imensurável e inseparável das relações. Os sistemas vivos nos ensinam a caminhar de forma integrada e equilibrada, a partir da conexão e interrelação entre todas as coisas. Devemos ver o impacto global de nossa existência individual, nunca esquecendo que vivemos ciclos contínuos e de renovação e, um fio que se solta pode significar consequências irrecuperáveis.

As obras citadas neste texto foram comparadas ao caminho percorrido pelas hifas, que vão se embrenhando pelo substrato e ampliando a rede de abrangência de espaços interligados, provocam reflexões a respeito das diversas ecologias e de novos caminhos que se cruzam. Não interessa de onde somos e como vivemos, nossas pequenas ações tornam-se fundamentais, todos fazemos parte de um grande ecossistema em que as interrelações afetam o todo, e qualquer desequilíbrio, onde quer que aconteça, poderá trazer consequências em pequenas ou grandes proporções.

A relação entre as obras pode provocar o pensamento sobre algo que atinge de forma generalizada as preocupações que perpassam o passado para atingir o contexto atual. As instalações citadas não revelam uma história específica, mas se abrem e se deslocam no tempo. A expressão do artista não diz respeito a um único fato, mas invoca a possibilidade de novos encontros.

As instalações dos dois artistas, apresentadas na $32^{\mathrm{a}}$ Bienal de São Paulo, evidenciam a complexa relação entre natureza e cultura. Ao associá-las, pretendeu-se ampliar a noção de integração dessas relações, através da percepção da realidade de um mundo transformado, globalizado, que procura o amadurecimento da consciência perceptiva do mundo, um mundo repleto de urgências em que o medo deve deslocar-se a partir de uma posição de alerta, para um posicionamento efetivo das questões que inquietam a todos.

São muitas as questões que hoje nos afligem, nos colocam em um mundo com inseguranças infinitas, onde experimentamos inquietações constantes diante da degradação ambiental, do esgotamento dos recursos naturais, das catástrofes naturais, das doenças, assim como pelas demais ameaças que assombram o futuro de nossas vidas.

Novas maneiras de relação com o mundo se tornam urgentes. Através da proposta dos artistas surgem oportunidades de ampliar leituras e direcionar ações. Uma época extremamente perturbadora, diante de um futuro incerto invade todo um planeta. A arte contemporânea propõe a democratização de todas as linguagens artísticas, com o intuito de que novas questões sejam levantadas, à medida que novos contextos são criados. 


\section{Referências:}

32 ${ }^{\mathrm{a}}$ BIENAL DE SÃO PAULO: Incerteza Viva: Catálogo/Organizado por Jochen Volz e Júlia Rebouças. São Paulo: Fundação Bienal de São Paulo, 2016.

$32^{\mathrm{a}}$ BIENAL DE SÃO PAULO. Incerteza Viva - Em'Kal Eyongakpa. Fundação Bienal, 2016. Disponível em: http://www.32bienal.org.br/pt/participants/o/2548 Acesso em: nov/2017.

BRENNER, Fernanda. 32 ${ }^{a}$ Bienal de São Paulo: declínio de afirmações, 2017. Disponível em: http://exhibitionist.kellenmorimotodesign.com/articles/assessments/32a-bienal-de-sao-paulo. Acesso em: jan/2020.

BUENAVENTURA, Júlia. Em'Kal Eyongakpa. 32a Bienal de São Paulo: Incerteza Viva - São Paulo: Fundação Bienal de São Paulo, 2016. 433p.

SHARJAH ART Foundation. Em'kal Eyongakpa: Select Words, 2016. Disponível em: http://sharjahart.org/sharjah-art-foundation/projects/emkal-eyongakpa-selected-works. Acesso em: fev/2020.

SUMMIT Saúde Brasil. Desmatamento pode favorecer novas pandemias. 13/05/2020. Medical News. Disponível em : https://summitsaude.estadao.com.br/desmatamento-pode-favorecer-novaspandemias/. Acesso em 20 de agosto de 2020

UFMT - Universidade Federal do Mato Grosso - Bienal da ecologia destaca debate sobre desequilíbrios socioambientais. 32ª Bienal - Itinerâncias: Cuiabá, 2017.

URBONAS, Nomeda e Gediminas. Psychotropic House: Zooetics Pavilion of ballardian Technologies. Disponível em: http://nugu.lt.kupranugaris.serveriai.lt/us/?p=399 . Acesso em: fev/2020

VOLZ, Jochen. Jornadas Espirais: Incerteza Viva. 32a Bienal de São Paulo: Incerteza Viva - São Paulo: Fundação Bienal de São Paulo, 2016. 433p.

VOLZ, Jochen. Entrevista concedida. Pinacoteca do Estado de São Paulo, 31 de outubro de 2019. 